\title{
Moving Beyond Satisfaction: Perceived Learning As An Assessment Measure
}

\author{
Gary M. Grudnitski, (E-mail: Gary.Grudnitski@SDSU.edu), San Diego State University
}

Kathleen A. Krentler, (E-mail: Kathleen.Krentler@SDSU.edu), San Diego State University

\begin{abstract}
Demand for assessment is growing. While satisfaction is often used as an outcome measure, it fails to recognize that satisfaction and learning may not be positively correlated. This study takes data originally collected with a focus on satisfaction, and reanalyzes it using student's perceptions of their learning as the outcome variable. Emphasis is placed on the impact of faculty-controlled or influenced variables on two types of learning. Satisfaction with the quality of faculty and instruction, breadth of curriculum, and class size are studied. All are found to significantly impact student's perceptions of both types of learning, with satisfaction of class size having the greatest effect.
\end{abstract}

\section{Introduction}

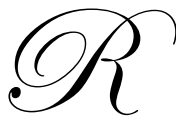

ecent increased calls by accrediting agencies have resulted in the development of a wide variety of approaches and measures to evaluate the extent to which institutions of higher learning are achieving their objectives. One frequently used assessment measure is satisfaction [Bauer and Bennett, 2003; Elliot, 2002-2003; Ellliot and Shin, 2002; Hong, 2002]. While satisfaction measures one aspect of success, it should be recognized that satisfaction, especially short-term student satisfaction, may not always equate to learning. Students may feel satisfied with an educational program without that program producing a level of learning that meets its academic objectives.

In the spring of 2003, the College of Business Administration at a large public University located in the southwestern part of the United States contracted with Educational Benchmarking Inc. (EBI) to conduct an exit survey of its undergraduate students. The survey was designed to measure the students' perceptions of and satisfaction with various aspects of their educational experience, including in-class experiences such as quality of teaching and learning outcomes, ancillary services such as advising and career services, and out-of-class experiences such as student organizations and the characteristics of their peers. Results from the survey, together with benchmarking data from comparable institutions, represent diagnostic tools to assist a college in developing a plan to improve its operations. Because satisfying customers, in this case students, is an important consideration for top college administrators, the survey results were anticipated to be particularly useful in providing direction for change.

Overall analysis of the results determined that students were moderately satisfied with their experience (a mean of 5.03 on a 7 point scale). While much detailed and useful information regarding students' levels of satisfaction with various aspects of their business education was provided by the survey results, some faculty were concerned that the focus on satisfaction did not measure the degree to which the institution was meeting its educational objectives. In short, what about learning?

The College of Business, in developing a comprehensive assessment plan, has sought to answer this question through the use of actual learning measures such as performance scores. Since the EBI study, however, did measure student's perceptions of their learning in addition to their satisfaction, it was felt that potentially useful 
insights could come from an analysis of the factors that contributed not only to student satisfaction but also to students' views of what they had learned.

The purpose of this paper is to begin to address the question of learning by looking at the existing EBI survey data through a lens that focuses on students' perceptions of learning outcomes rather than exclusively on student satisfaction. Particular attention is given to the role faculty play in the achievement of perceived learning outcomes. Our examination also includes consideration of class size, an additional variable that can affect what happens in the classroom, and hence student learning outcomes.

\title{
Learning As An Outcome
}

Learning is a complex concept generally believed to be influenced by a myriad of factors. Wang et al. [1993-1994] reviewed fifty years of research on the topic. Their review uncovered more than 11,000 statistical findings regarding the most significant influences on learning. The result of Wang et al.'s research was a conceptual framework that includes 28 categories of learning influences. They grouped these 28 categories into six broad types of influence:

\author{
- $\quad$ Student Aptitude \\ - $\quad$ Classroom Instruction and Climate \\ - Context \\ - $\quad$ Program Design \\ - $\quad$ School Organization \\ - $\quad$ State and District Characteristics
}

Of these six influence types, student aptitude, classroom instruction and climate, and context appear to have the greatest impact on student learning. The literature generally found program design and school organization to have moderate influences on learning, and State and District characteristics to have limited influence on learning. Because our research is interested in factors that are controlled by faculty or affect what happens in the classroom, only the influence categories of classroom instruction and climate and program design will receive further consideration.

Classroom instruction and climate has been found in numerous contexts to strongly influence actual student learning and student's perceptions of their learning. This category includes style, means, and quality of instruction as well as the frequency and quality of instructor/student interaction. Size of class or student/faculty ratio generally affects interaction and hence is also included in this category. The National Survey of Student Engagement [Indiana University, 2001] has identified level of academic challenge (instruction) and student-faculty interaction to be two of the five primary activities associated with positive student learning outcomes. Further, Hoyt and Lee [2002] examined six teaching styles and found that some styles are positively associated with specific types of learning but that no teaching style was consistently associated with stronger learning across all types of learning objectives. Prosser et al. [2003] found higher quality teaching, defined as more coherent and more consonant, produced perceptions of more and deeper learning among college students. Student-faculty interaction both in and outside the classroom has been found in numerous studies to influence student's perceptions of their learning with the general consensus supporting that the higher the quantity and/or quality the interaction, the more students perceive they have learned [Swan et. al, 2000; Richardson \& Ting, 1999; Picciano, 1998; Jiang \& Ting, 1998].

Program design has been shown to have a moderate influence on student learning as well as students' perceptions of their learning. In the current study the specific aspect of program design considered is breadth of curriculum. In an examination of curriculum development, Hirsch [2001] points out that the literature supports the need for educators to seek breadth as well as depth in program design - the best way to learn a subject is to learn its general principles and then to study diverse examples that illustrate these principles across diverse applications. Inkelas and Weisman [2003] found that students exposed to a broader curriculum through a living-learning environment exhibited stronger academic outcomes as well as higher levels of engagement. Tucker et al. [1998] piloted a program that provided computer science majors with a "breadth first curriculum" and found desirable 
results with respect to learning outcomes. Swan et. al, [2000] found that the more consistent the design of courses across the breadth of a program, the greater student's perceptions of their learning.

Based on the existing literature with respect to learning outcomes and student's perceptions of learning and using the available data from the EBI survey, the following hypotheses were investigated in this study:

Ho\#1: Students who rate faculty and instruction highly will perceive that they have an enhanced level of learning.

Ho\#2: Students who are more satisfied with the size of their classes will perceive that they have an enhanced level of learning.

Ho\#3: Students who are more highly satisfied with the breadth of the business curriculum will perceive that they have an enhanced level of learning.

\section{Method}

The EBI instrument from which the data used for this study was drawn has been proven reliable and valid, and used regularly by Educational Benchmarking Incorporated. ${ }^{1}$ Data was collected from 283 graduating seniors enrolled in capstone courses across the five departments in the College of Business. All majors offered in the College were represented. The data was collected during class time and responses were anonymous. Initial analysis of the data using satisfaction as the primary dependent variable was performed by EBI. The additional analyses that provided the basis of the current study were performed within the College of Business.

The original EBI instrument utilized eleven learning outcomes (see Appendix I). To reduce these to a more manageable number, a factor analysis was performed. From the eleven learning outcome items, two factors emerged as shown in Table 1. Both factors are composed of a single dimension. No significant cross loads were found, and the minimum factor loadings exceeded 0.6 for all items, implying convergent and discriminate validity for the constructs.

Table 1: Results of Exploratory Factor Analysis on the Learning Outcome Questions

\begin{tabular}{|l|c|c|}
\hline Question & Factor 1 -Applied Learning (AL) & Factor 2 - Cognitive Learning (CL) \\
\hline Presentation Skills (L1) & .631 & \\
\hline Writing Skill (L2) & .613 & \\
\hline Work in Teams (L3) & .614 & \\
\hline Use Technology (L4) & .782 & \\
\hline Manage Technology (L5) & .815 & \\
\hline Effective Manager (L6) & .709 & .744 \\
\hline Effective Leader (L7) & .709 & .878 \\
\hline Think Critically (L8) & & .866 \\
\hline Define Problems (L9) & & .753 \\
\hline Solve Problems (L10) & & \\
\hline Analyze \& Interpret Data (L11) & & \\
\hline Eigenvalue & & \\
\% of variance 56.168 1.069 9.72 & & \\
\hline
\end{tabular}

The two factors that emerged from the eleven learning outcomes appeared to represent clearly distinct types of learning. Factor 1 includes items directly related to externally demonstrable skills such as presentation skills, writing skills, and teamwork skills, hence was identified as Applied Learning. Factor 2, on the other hand, was composed of items directly related to internal abilities - critical thinking, problem solving, analysis abilities, and hence was identified as Cognitive Learning.

\footnotetext{
${ }^{1}$ Further information on EBI, its services, and the instruments it uses can be obtained from Educational Benchmarking Inc., $1630 \mathrm{~W}$. Elfindale, Springfield, MO 65807, 417-831-1810, www.webi.com
} 
The distinction between what has been termed here Applied Learning and Cognitive Learning is supported in the learning literature. DeCorte [1995] identifies a distinction between "skilled learning" (i.e., Applied Learning) and "thinking" (i.e., Cognitive Learning). The former includes domain-specific knowledge as well as rules and concepts [Glaser, 1991]. Recent trends toward outcome-based assessment measure levels of Applied Learning by evaluating what individuals can do in actual or simulated applied situations [Bergen, 1993-94]. The dimension of Cognitive Learning is equated in the literature to critical thinking. Downs [1993] states, "Critical thinking is the process of actively and skillfully conceptualizing, applying, analyzing, synthesizing, or evaluating information." Sormunen [1993] further points out that, "... developing critical thinking skills will enhance the learning process."

Figure 1: Conceptual Model

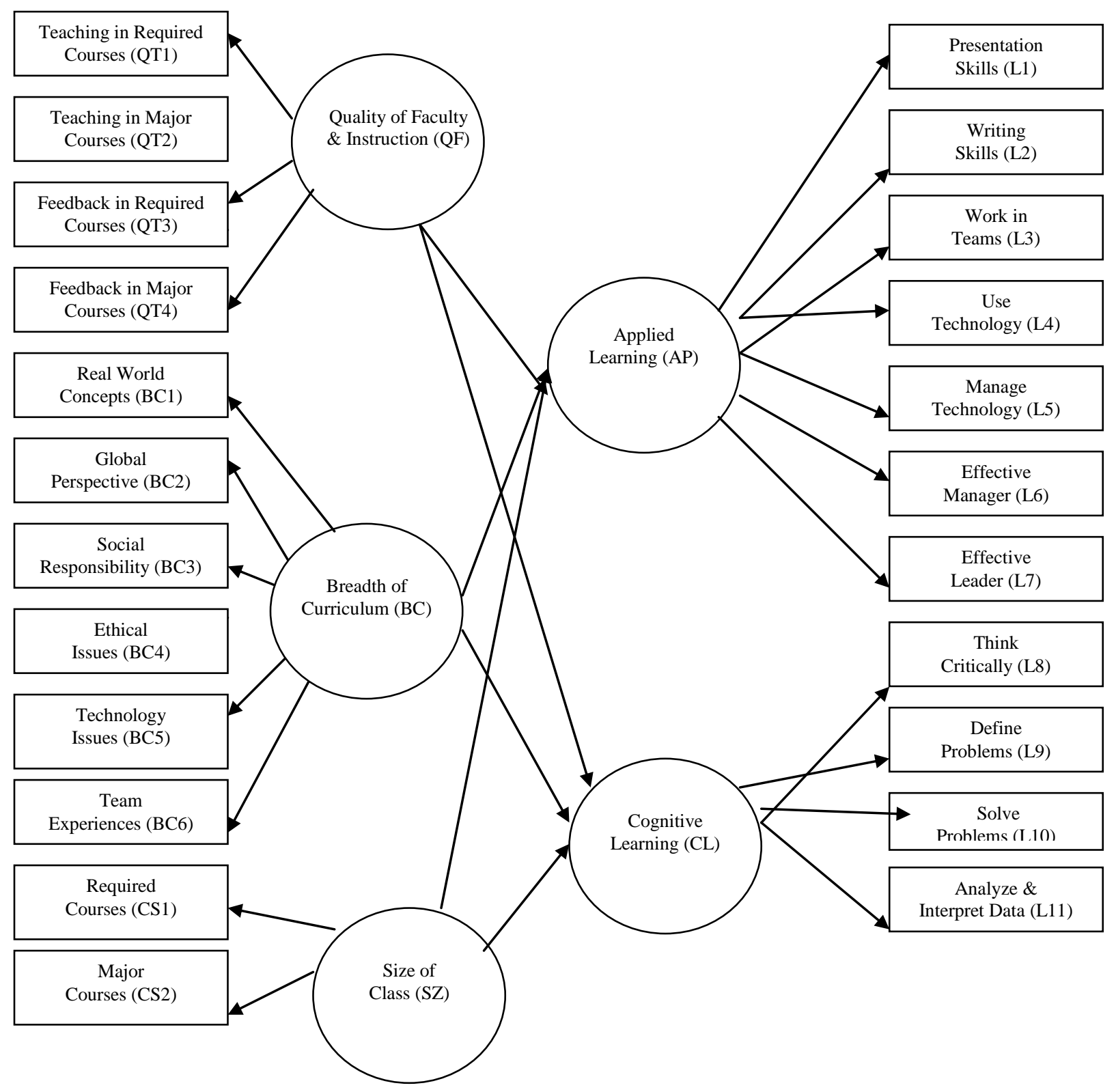


To estimate the multiple and interrelated dependence relationships described above, Structural Equation Modeling (SEM), a multivariate statistical technique, was chosen. SEM can represent unobserved concepts called latent variables in these relationships and account for measurement error in the estimation process.

SEM embraces two submodels: a measurement model and a structural model. The measurement model of SEM focuses on evaluating the contribution of observed scores on measurement questions listed in Appendix I and II, (i.e., the manifest variables) to the underlying constructs (the latent variables). The structural model of SEM is the "path" model that defines relationships among the unobserved variables. That is, its objective is to specify which independent or exogenous latent variables cause changes in the values of the latent dependent or endogenous variables in the model.

As a result of the identification of the two learning types, the three hypotheses were each divided and the conceptual model portrayed in Figure 1 was used for further analysis.

Ho\#1a: Students who rate faculty and instruction highly will perceive that they have an enhanced level of applied learning.

Ho\#1b: Students who rate faculty and instruction highly will perceive that they have an enhanced level of cognitive learning.

Ho\#2a Students who are more satisfied with the size of their classes will perceive that they have an enhanced level of applied learning.

Ho\#2b: Students who are more satisfied with the size of their classes will perceive that they have an enhanced level of cognitive learning.

Ho\#3a: Students who are more highly satisfied with the breadth of the Business curriculum will perceive that they have an enhanced level of applied learning.

Ho\#3b: Students who are more highly satisfied with the breadth of the Business curriculum will perceive that they have an enhanced level of cognitive learning.

\section{Results}

\section{Measurement Model}

Table 2 gives the means, variances and reliability estimates [Cronbach, 1951] for the endogenous and exogenous constructs, respectively. All reliabilities are above 0.75 with the majority above 0.80 , exceeding generally accepted basic research reliability standards.

Table 2: Statistical Attributes of the Latent Constructs

\begin{tabular}{|c|c|c|c|c|}
\hline Scale & \# of Items & Mean & Variance & Reliability \\
\hline Quality of Teaching & 4 & 4.46 & .095 & .814 \\
\hline Satisfaction with the Breadth of Curriculum & 6 & 5.18 & .004 & .833 \\
\hline Satisfaction with the Size of Class & 2 & 4.89 & .309 & .752 \\
\hline Enhanced Applied Learning & 7 & 5.01 & .036 & .877 \\
\hline Enhanced Cognitive Learning & 4 & 5.53 & .002 & .905 \\
\hline
\end{tabular}

Structural equation modeling implemented through AMOS (Analysis of MOment Structures) tested the relationships depicted in Figure 1. To assess the overall fit of the model, various standard measures of absolute, incremental, and parsimonious fit were used [Joreskog and Sorbom, 1984; Tanaka and Huba, 1985; Chau, 1997; Bentler and Bonnet, 1980; Byrne, 1989]. Model fit measures included goodness of fit index (GFI), adjusted goodness of fit index (AGFI), normed fit index (NFI), root mean square error of approximation (RMSEA), and normed chi-square value. Values of the first three indices range from 0 (no fit) to 1 (perfect fit), with values of 0.80 or above considered acceptable and representing a good model fit. For the index of RMSEA, a smaller value is considered to be evidence of a good model fit. Finally, a normed chi-square value between 1 and 3 indicates the 
model fits the data well [Hong et al., 2002]. Table 3 summarizes the results of this analysis for the hypothesized model.

Table 3: Fit Indices of the Hypothesized Model

\begin{tabular}{|l|l|c|}
\hline Index & \multicolumn{1}{|c|}{ Description } & Model Value \\
\hline GFI & Goodness of fit & 0.859 \\
\hline AGFI & Adjusted goodness of fit & 0.803 \\
\hline NFI & Normed fit index & 0.832 \\
\hline RMSEA & Root mean square error of approximation & 0.096 \\
\hline$X^{2} /$ df & Normed chi-square & 2.770 \\
\hline
\end{tabular}

Table 4 lists the standardized regression weights of the five latent variables and their manifest variables, as well as statistics representing the level of significance of the coefficients. The standardized regression weights represent estimates of the change in the manifest variables related to changes in the latent variables. The level of significance statistics shown in the table are constructed by comparing the estimated parameter to its standard error and are assumed to have a t-distribution [Marsch and Hocevar, 1985].

Table 4: Regression Coefficients between the Latent and Manifest Variables

\begin{tabular}{|l|c|c|c|}
\hline Relationship & Standardized Regression Coefficient & t-value & Significant \\
\hline $\mathrm{QF} \rightarrow \mathrm{QT1}$ & .592 & 9.73 & yes \\
\hline $\mathrm{QF} \rightarrow \mathrm{QT2}$ & .648 & 10.75 & yes \\
\hline $\mathrm{QF} \rightarrow \mathrm{QT} 3$ & .764 & 12.60 & yes \\
\hline $\mathrm{QF} \rightarrow \mathrm{QT} 4$ & .874 & 13.36 & yes \\
\hline $\mathrm{BC} \rightarrow \mathrm{BC} 1$ & .468 & 4.48 & yes \\
\hline $\mathrm{BC} \rightarrow \mathrm{BC} 2$ & .713 & 5.05 & yes \\
\hline $\mathrm{BC} \rightarrow \mathrm{BC} 3$ & .897 & 5.21 & yes \\
\hline $\mathrm{BC} \rightarrow \mathrm{BC} 4$ & .804 & 5.16 & yes \\
\hline $\mathrm{BC} \rightarrow \mathrm{BC5}$ & .601 & 4.85 & yes \\
\hline $\mathrm{BC} \rightarrow \mathrm{BC6}$ & .323 & 3.30 & yes \\
\hline $\mathrm{SZ} \rightarrow \mathrm{CS} 1$ & .356 & 3.73 & yes \\
\hline $\mathrm{SZ} \rightarrow \mathrm{CS} 2$ & .332 & 3.46 & yes \\
\hline $\mathrm{AL} \rightarrow \mathrm{L} 1$ & .594 & 7.50 & yes \\
\hline $\mathrm{AL} \rightarrow \mathrm{L} 2$ & .548 & 7.72 & yes \\
\hline $\mathrm{AL} \rightarrow \mathrm{L} 3$ & .577 & 8.04 & yes \\
\hline $\mathrm{AL} \rightarrow \mathrm{L} 4$ & .657 & 8.87 & yes \\
\hline $\mathrm{AL} \rightarrow \mathrm{L} 5$ & .715 & 9.41 & yes \\
\hline $\mathrm{AL} \rightarrow \mathrm{L} 6$ & .837 & 10.40 & yes \\
\hline $\mathrm{AL} \rightarrow \mathrm{L} 7$ & .847 & 10.47 & yes \\
\hline $\mathrm{CL} \rightarrow \mathrm{L} 8$ & .780 & 12.46 & yes \\
\hline $\mathrm{CL} \rightarrow \mathrm{L} 9$ & .907 & 14.35 & yes \\
\hline $\mathrm{CL} \rightarrow \mathrm{L} 10$ & .910 & 14.39 & yes \\
\hline $\mathrm{CL} \rightarrow \mathrm{L} 11$ & .708 & 11.89 & \\
\hline
\end{tabular}

A review of the t-values in Table 4 demonstrates all of the links between the latent and manifest variables of the model are significant at the 0.001 level, and represent strong positive relationships between these constructs and their manifest variables. Moreover, it appears that several of the latent variables are more strongly influenced by a subset of their manifest variables. For example, the latent variable of quality of faculty appears to be more affected by both feedback questions than the questions about the quality of teaching. The latent variable of breadth of the curriculum appears most heavily influenced by the variables asking about the students' satisfaction with business curriculum instructors presenting a global prospective, social responsibility issues, and ethical issues. Finally, the learning latent variables appear to be most affected by variables measuring the degree to which the business program 
enhanced a student's ability to be an effective manager and leader (Applied Learning), and ability to define and solve problems (Cognitive Learning).

\section{Structural Model}

The structural model is the path model that defines the relationships between the exogenous latent (independent) variables of quality of faculty, breadth of curriculum and size of class and the endogenous latent (dependent) variables of cognitive and applied learning. Table 5 lists the path coefficients (i.e., the standardized regression weights) of the model linking the independent latent variables to the dependent latent variables.

Table 5: Path-Analytic Results of the Hypothesized Model

\begin{tabular}{|l|c|c|c|c|}
\hline Hypothesis & Relationship Hypothesized & Standardized Regression Coefficient & t-value & Significant \\
\hline $1 \mathrm{a}$ & $\mathrm{QF} \rightarrow \mathrm{AL}$ & .227 & 3.57 & yes \\
\hline 1b & $\mathrm{QF} \rightarrow \mathrm{CL}$ & .205 & 3.36 & yes \\
\hline 2a & $\mathrm{BC} \rightarrow \mathrm{AL}$ & .278 & 3.39 & yes \\
\hline 2b & $\mathrm{BC} \rightarrow \mathrm{CL}$ & .382 & 4.03 & yes \\
\hline 3a & $\mathrm{SZ} \rightarrow \mathrm{AL}$ & .840 & 4.56 & yes \\
\hline 3b & $\mathrm{SZ} \rightarrow \mathrm{CL}$ & .627 & 4.46 & yes \\
\hline
\end{tabular}

A review of the t-values in Table 5 reveals all of the paths represent positive relationships between the independent and dependent constructs specified in our model, are highly significant (i.e., at the 0.001 level), and support all six hypotheses.

In reviewing the regression weights, the dominant exogenous latent variable that appears to have the greatest impact on the endogenous variables is size of class. Specifically, class size is estimated to have about twice the effect on cognitive learning when compared to either quality of faculty or breadth of the curriculum. Even more dramatically, class size is estimated to have more than three times the effect of either quality of faculty or breadth of the curriculum in enhancing the students' perception of their applied learning capabilities.

\section{Implications For Program Administrators And Teaching Faculty}

Based on the results of the measurement model, faculty would do well to note that while clearly their teaching is a significant factor affecting perceived learning, the feedback they provide on assignments may have a bigger impact on what their students believe they have learned. Moreover, because an inverse relationship may exist between the number of students a faculty member teaches and the amount of feedback he or she provides these students on assignments, as class size rises and the amount of feedback provided concurrently decreases, a further diminution of student learning is likely to result, at least from the students' perspectives.

The results of the measurement model appear to be consistent with the results from the structural model, which suggest that class size is by far the dominant variable in explaining both cognitive and applied learning. As the level of satisfaction with class size increases, presumably as the result of smaller classes, students' perceptions of their levels of applied and cognitive learning increase dramatically. This finding is intuitively supported by consideration of the types of classroom assessments most likely to be used in larger classes (e.g., multiple-choice exam questions), which may logically hinder the enhancement of cognitive skills. Sormunen [1992] states, "Critical thinking is best developed in business courses through case studies, group projects, simulations, computer applications, role playing, and other techniques." Correspondingly, substituting multiple-choice assignments for these types of activities creates a reduced opportunity set to provide constructive feedback to help students develop their applied skills. 


\section{Conclusions}

The current study represents an attempt to reorient the analysis of a variety of factors associated with assessing higher education, moving away from student satisfaction and towards learning outcomes. While members of the higher education community, especially administrators, are unlikely to choose to ignore student satisfaction completely (nor should they), a focus on learning outcomes is crucial to the development and refinement of efforts that contribute strongly to the achievement of desired learning objectives.

This paper is limited in its effort to consider learning outcomes by the fact that the available data measured only students' perceptions of their learning. While this represents movement in the right direction, we believe that the logical extension of this research is to investigate the relationships defined here using objective measures of students' actual learning.

The present study suggests that a variety of faculty controlled and faculty influenced factors affect students' perceptions of their learning and potentially by inference, their actual learning. This latter point, as noted in the above discussion of the limitation of this study, needs to be investigated with actual learning measures before anything conclusive can be stated however. What instructors do in their classrooms and the feedback they provide their student's does make a difference in what students believe they learn. Further, the nature of the curriculum offered to students also influences their perceived learning. Most dramatically, however, the number of students in a class influences perceived learning. Consequently, in the face of building economic pressures for larger class sizes, the trade-off between class size and achieving learning objectives will only become a more difficult decision for higher education leaders.

\section{References}

1. Bauer, K.W. and J.S. Bennett. "Alumni Perceptions Used to Assess Undergraduate Research Experience," Journal of Higher Education, 7, (No. 2, 2003), 210-230.

2. Bentler, P.M. and D.G. Bonnet. "Significance Tests and Goodness of Fit in Analysis of Covariance Structures," Psychological Bulletin, 88, (1980), 588-606.

3. Bergen, D. "Authentic Performance Assessments," Childhood Education, 70, (No. 2, 1992-1993), 99-102.

4. Byrne, B.M. A Primer of LISREL: Basic Applications and Programming for Confirmatory Factor Analysis Models. New York, Springer-Verlag, (1989).

5. Chau, P.Y.K. "Reexamining a Model for Evaluating Information Center Success Using a Structural Equation Modeling Approach," Decision Sciences, 28, (No. 2, 1997), 309-334.

6. Cronbach, L.J. "Coefficient Alpha and the Internal Structure of Tests," Psychometrica, 16, (1951), 297 334.

7. De Corte, E. "Learning Theory and Instructional Science," In Reimann, P. and H. Spada (eds.), Learning in Humans and Machines: Towards an Interdisciplinary Learning Science. 97-108. Tarrytown, NY: Elsevier Science Inc. (1995).

8. Downs, J.R. A Mini-Workshop in Critical and Creative Thinking. Florida, (1993).

9. Elliot, K.M. "Key Determinants of Student Satisfaction," Journal of College Student Retention, 4, (No. 3, 2002-2003), 271-279.

10. Elliot, K.M. and D. Shin. "Student Satisfaction: An Alternative Approach to Assessing This Important Concept," Journal of Higher Education Policy and Management, 24, (No. 2, 2002), 197-209.

11. Glaser, R. "The Maturing of the Relationship Between the Science of Learning and Cognition and Educational Practice," Learning and Instruction, 1, (No. 2, 1991), 129-144.

12. Hirsch, E.D. Educational Leadership, 59, (2001), 22-25.

13. Hong, K.S. "Relationships between Students' and Instructional Variables with Satisfaction and Learning from a Web-Based Course," Internet and Higher Education, 5, (No. 3, 2002), 267-281.

14. Hong, W., J.Y. Thong, W. Wong and K. Tam. "Determinants of User Acceptance of Digital Libraries: An Empirical Examination of Individual Differences and System Characteristics," Journal of Management Information Systems, 18, (No.3, 2002), 97-124. 
15. Hoyt, D.P. and E.J. Lee. “Teaching 'Styles' and Learning Outcomes,” IDEA Research Report, (2002), Kansas State University, Manhattan, IDEA Center, 11-00.

16. Indiana University, School of Education. Improving the College Experience: National Benchmarks of Effective Educational Practice; NSSE 2001 Report. National Survey of Student Engagement: The College Student Report. Bloomington, IN., Publication: U.S.; Indiana; 11-00, (2001).

17. Inkelas, K.K. and J.L. Weisman. (2003), "Different by Design: An Examination of Student Outcomes among Participants in Three Types of Living-Learning Programs," Journal of College Student Development, 44, (No. 3, 2003), 335-368.

18. Jiang, M. and E. Ting. (1998), "Course Design, Instructions and Students' Online Behaviors: A Study on Course Variables and Students' Perceptions of Online Learning." Paper presented at Annual Meeting of the American Educational Research Association, San Diego.

19. Joreskog, K.G. and D. Sorbom. LISREL Analysis of Structural Relationships by the Method of Maximum Likelihood. Scientific Software, Inc. Moorsville, IN. (1984).

20. Marsch, H.W. and D. Hocevar. "Application of Confirmatory Factor Analysis of the Study of Self-concept: First and Higher Order Factor Models and Their Invariance across Groups," Psychological Bulletin, 97, (1985), 562-582.

21. Picciano, A. (1998). "Developing an Asynchronous Course Model at a large, Urban University," Journal of Asynchronous Learning Networks," 2(1).

22. Prosser, M., P. Ramsden, K. Trigwell and E. Martin. "Dissonance in Experience of Teaching and Its Relation to the Quality of Student Learning," Studies in Higher Education, 28, (No.1, 2003), 37-48.

23. Richardson, J. and E.Ting (1999). "Making the Most of Interaction: What Instructors do that Most Affect Students' Perceptions of their Learning," Paper presented at the $5^{\text {th }}$ International Conference on Asynchronous Learning, College Park, MD.

24. Sormunen, C. Critical Thinking in Business Education, Indiana, United States, (1992).

25. Swan, K., P. Shea, E.E. Fredericksen, A.M. Pickett, and W.E. Pelz, (2000). "Course Design Factors Influencing the Success of Online Learning." Paper presented at World Conference on the WWW and Internet, San Antonio, TX.

26. Tanaka, J.S. and G.J. Huba. "A Fit Index for Covariance Structure Models under Arbitrary GLS Estimation," British Journal of Mathematical and Statistical Psychology, 38, (1985), 197-201.

27. Tucker, A.B., K.Barker, and A.P. Bernat. "Developing the Breadth-First Curriculum: Results of a Threeyear Experiment," Computer Science Education, 8, (No. 1, 1998), 27-55.

28. Wang, M.C., G.D. Haertel and H.J. Walberg. "What Helps Students Learn?" Educational Leadership, (1993-1994). 


\section{Appendix I: Learning Outcome Items*}

L1. To what extent did the business program enhance your presentation skills?

L2. To what extent did the business program enhance your writing skills?

L3. To what extent did the business program enhance your ability to work in teams?

L4. To what extent did the business program enhance your ability to use technology?

L5. To what extent did the business program enhance your ability to manage technology?

L6. To what extent did the business program enhance your ability to be an effective manager?

L7. To what extent did the business program enhance your ability to be an effective leader?

L8. To what extent did the business program enhance your ability to think critically?

L9. To what extent to which the business program enhance your ability to define problems?

L10. To what extent did the business program enhance your ability to solve problems?

L11. To what extent did the business program enhance your ability to analyze and interpret data?

* Questions were measured on a 7 point scale where $1=$ Not at All and $7=$ Extremely.

\section{Appendix II: Faculty Controlled/Influenced Items*}

QT1. Quality of teaching in your required courses.

QT2. Quality of teaching in your major courses.

QT3. Quality of feedback on assignments (other than grades) received from instructors in your required courses.

QT4. Quality of feedback on assignments (other than grades) received from instructors in your major courses.

BC1. Satisfaction with required course instructors relating concepts to the real world.

BC2. Satisfaction with business curriculum instructors presenting a global perspective.

BC3. Satisfaction with business curriculum instructors presenting social responsibility issues.

BC4. Satisfaction with business curriculum instructors presenting ethical issues.

BC5. Satisfaction with business curriculum instructors presenting technology issues.

BC6. Satisfaction with value derived from team experiences.

CS1. Satisfaction with average size of required courses.

CS2. Satisfaction with average size of major courses.

* Questions 1-4 were measured on a 7 point scale where $1=$ Very Poor and $7=$ Exceptional; questions 5-12 were measured on a 7 point scale were $1=$ Very Dissatisfied and $7=$ Very Satisfied. 